\title{
Numerical Study of Savonius Wind Turbine with Fluid-Rotor Interactions
}

\author{
Zain Lillahulhaq ${ }^{1}$, Vivien Suphandani Djanali ${ }^{1}$
}

\begin{abstract}
Previous numerical studies in the Savonius wind turbine mostly used constant angular velocity as input data, where the values were obtained from experiments. This process cannot be used in the design optimization of the turbine, in which the angular velocity of the modified turbine is not known a priority. In numerical simulation, the use of loading system to get constant angular velocity to control the tip speed ratio (TSR), tends to have fluctuating value on output data. Moreover, the values of angular velocity shall be the results from freestream flow and Savonius rotor interaction. This condition can be simulated by using fluid structure interaction (FSI) method. Three dimensional Savonius $S$ wind turbine is simulated using unsteady Reynolds Averaged Navier Stokes (RANS). Inlet velocity and wind turbine inertia are used as input data. The flow is assumed to be incompressible, viscous, and uniform at the inlet. The turbulence model used is the Eddy Viscosity k- $\omega$ SST, with $y^{+}<1$. The domain consists of a sliding mesh, which rotates in the overset mesh region. Simulation results Power Coefficient (CP) and angular velocity and compared with experimental result. This study is resulted a standard method for the Savonius wind turbine numerical study.
\end{abstract}

Keywords-Fluid Structure Interaction, Coefficient Power, Tip Speed Ratio.

\section{INTRODUCTION}

In this century, alternative energy source are commonly use in small scale to replace fossil energy and reduce global warming effect. Wind is one of alternative energy that human can be convert to electricity using. Wind turbines are classified as vertical axis wind turbine (VWAT) and horizontal axis wind turbine (HWAT) based on rotating direction. Savonius turbine is a VWAT model which rotates by drag force in low wind velocity from any direction. Moreover Savonius turbine does not need yaw mechanism and high tower to set up. Furthermore it has self-starting ability and only produces little noise, so this turbine can be applied in urban with crowd and narrow area[1]. However Savonius turbine has lower efficiency compared to the HWAT model such as Darrieus turbine. Based on these advantages, many researchers concern to increase Savonius turbine efficiency.

Savonius blades are made from two of half circular which paired in adverse direction. Savonius wind turbine is quite easy to make for experiment research. Along with the improvement of computational technology, numerical study can used to get qualitative and quantitative data. Numerical

\footnotetext{
${ }^{1}$ Zain Lillahulhaq and Vivien Suphandani Djanali are with Mechanical Engineering Department, Institut Teknologi Sepuluh Nopember, Surabaya, $60111 \quad$ Indonesia. E-mail: lillahulhaqzain@gmail.com; vivien_dj@yahoo.com.
}

study can be done in a relative short time, inexpensive and high accuracy, if it set in proper steps.

Generally Savonius wind turbine performance is represent in non-dimensional numbers, such as Tip speed ratio (TSR), Coefficient power (CP), and Coefficient torque (CQ). TSR is non-dimensional number to describe velocity which can be obtained by divide freestream velocity with constant angular velocity. The value of angular velocity is obtained from previous experiment study. To get CP and CQ as TSR function, wind turbine should be rotating in constant angular velocity by giving break or load to the rotor axis[2]. Constant angular velocity rise along with TSR increment. In numerical study constant angular velocity are used as input data as sliding mesh rotating velocity. Using loading system to get constant angular velocity in TSR causes fluctuating value in output data[3]. Angular velocity should be the result of interaction between freestream and Savonius blade in numerical study. Furthermore TSR number is difficult to be approximated in numerical study, if there are no angular velocity data from previous experiment study.

Numerical studies are enable researchers to solve 2D or 3D Savonius wind turbine in steady or unsteady condition. Numerical study is used to studied overlap effect to CP in 2D Savonius wind turbine[4]. This unsteady simulation use STAR CCM+ sliding mesh in constant Re 4.32 x 105. The value of inlet and angular velocity are constant adjusted to Re number. Reynolds Averaged Naviere Stokes (RANS) and Eddy Viscosity k- $\omega$ SST are selected as equation and turbulence model. Simulation results are validated by Sheldahl experiment and result error 2.26\%. Using k- $\omega$ SST to receive high accuracy also proven in $2 \mathrm{D}$ steady and unsteady Savonius wind turbine simulation[5]. Two experiment geometry data are referenced from Sheldahl (1997) and Fujusiwa (1992) experiment. Both studies above are not using DBFI method, but it use sliding mesh method in constant angular velocity.

FSI method applies to discover loading effect in three dimensional numerical study of Savonius wind turbine[6]. This unsteady simulation use rigid body solver sliding mesh and inlet velocity has constant. Loading condition in wind turbine determine as external torque which rotate in opposite direction. Unloading wind turbine reaches steady condition faster than loading condition in same TSR. Turbulence model and validation process are not state in briefly.

Numerical steps of Savonius wind turbine simulation in 1-DOF DBFI method are applied by using polyhedral mesh[7]. In the research, 2 blades straight Savonius is 
simulated in STAR CCM+ program. Interface interaction between two regions will be compute in sliding mesh method. Polyhedral mesh is applied two layers with growth rate ratio to get $\mathrm{y} \approx+5$. Standard $\mathrm{k}-\varepsilon$ and STT $\mathrm{k}-\omega$ are compared to make closest prediction base on experimental data. The result shows that STT k- $\omega$ gives closest moment coefficient value, although both of these simulation models have similar trend line. STT k- $\omega$ suit to use to get closest data compared by experiment, even k- $\varepsilon$ give better result in showing vortex effect[8].

Fluid structure interaction (FSI) method can be used to avoid using constant angular velocity value as input data in numerical study. FSI method consider force and deflection which effected by stream around the structure. Angular velocity is not used as input data in FSI method, but it require mass and inertia moment. This paper observe interaction between freestream around Savonius blade which able to rotate wind turbine in its axis (1- DOF). The result of FSI-1 DOF BDFI is compered with static simulation. Commercial computational program is used to simulate 3D straight Savonius in unsteady model with FSI method. This study is focused to simulate Savonius wind turbine in FSI 1-DOF on valid method. Moreover the result show close value compared by experimental reference.

\section{METHOD}

\section{A. Numerical Method}

Savonius wind turbine model can be drawn in commercial design program. Dimension of Savonius wind turbine in this paper refer to saha's experimental study[9]. The boundary area is drawn in complete form using computational program with dimension in Figure 1 . Meshing is priority process in this numerical study. This simulation uses trimmer surface remesher model. There are two mesh domains in this simulation which conduct of test section and overset area. Prism layer option is selected to get $\mathrm{y}^{+}<1$ and the number of layer are 10. Grid independency process is held to get optimum number of cells to get exact result. The number of cells which used in grid independency process is ranged in 600000-1100000. Mesh that used in this study shown in Figure 2. Some constrains and equations are needed to solve numerical simulation. Boundary condition which used in this simulation is shown in Table 1. This meshing is used to simulated static and 1-DOF simulation.

Static simulation run by using different models of Savonius windturbin in different azimuth angel. The average of $C_{P}$ and $C_{Q}$ value from different azimuth angel are taken as total result value of static simulation. The result of static simulation will be compared with 1-DOF simulation.

1-DOF simulation run in unsteady condition with different time step. This simulation used Reynolds Averaged Naviere Stokes (RANS) in STT k- $\omega$ turbulance model. In this study, the optimum value of $C_{P}$ and $C_{Q}$ are taken from graphics trenline.
Incremental time in integral calculation step called time step. In grid independency test, time step are dependence to interval cell. Time step is decreasing along with increment of cell number. Time step for grid independency test are shown in Table 2.

\section{B. Mathematics}

Savonius performance can be calculated based on angular rotation and torque value directly. Moreover simulation data results are represented in non-dimensional graphics to express the Savonius turbine performance. Nondimensional numbers that represent Savonius wind turbine performance are Tip speed ratio (TSR), Coefficient power $\left(\mathrm{C}_{\mathrm{P}}\right)$, and Coefficient torque $\left(\mathrm{C}_{\mathrm{Q}}\right)$, as shown in the following equation:

$$
\begin{aligned}
& \text { TSR }=\frac{\omega \cdot d}{v} \\
& C_{p}=\frac{T \cdot \omega}{\frac{1}{2} \rho \cdot D \cdot H \cdot v^{3}} \\
& C_{q}=\frac{T_{\text {actual }}}{\frac{1}{4} \rho \cdot A_{s} \cdot d \cdot v^{2}}
\end{aligned}
$$

1-DOF study needs mass and inertia moment as input data to run the simulation. Occasionally, the value of mass and inertia moment are not stated in some numerical literature. Actually mass and inertia moment can be found from dimension with this following equation[10].

$$
\begin{aligned}
& m=\frac{\pi}{2} . \rho . H . t . d \\
& I_{3 b}=\frac{4}{\pi} m \cdot d^{2}
\end{aligned}
$$

Meanwhile for 2 endplates for Savonius wind turbine, the inertia is stated as equation below:

$$
I_{2 p}=\frac{2}{12} m \cdot r^{2}
$$

Partial differential equations which use in numerical study are dependent to convection equation including distance and time. CFL number should be consider to get stability and convergence solution. Maximum value of CFL number for the dynamic simulation and implicit Euler integration is 5.

$$
C=\frac{v \cdot \Delta t}{\Delta x} \leq C_{\text {max }}
$$

\section{RESUltS AND DISCUSSION}

This simulation runs until reach steady condition. Angular velocity and moment are not shown significant increment in steady condition. Numerical results are compared simulation result to get optimum cell numbers in grid independency process. The results are shown in following Table 3. It shows that using 1.100 .000 mesh in a simulation is resulted stable data.

In unsteady 1-DOF simulation the simulation result angular velocity and moment graphics as physical time function shown Figure 3. Angular velocity adn moment value can be exported to non-dimensional value such $C_{P}$ and $C_{Q}$ as TSR function in Figure 4. Unsteady simulation uses high timestep in the begining of running process to 
reduce total running time. The time step will be reduce countinusly when the data show slight deviation. If simulation hihgher timestep than CFL number, it will result unstable data. Export data to non-demensional value will reduce unstable condition that resulted by time step changing process. Moreover non-dimensional simulation result won't be influance by inlet fluid characterictic.

Static and 1-DOF $\mathrm{C}_{Q}$ value in 0 TSR are shown in Table 3. Static simulation result higher $C_{Q}$ value compared with 1-DOF simulation.

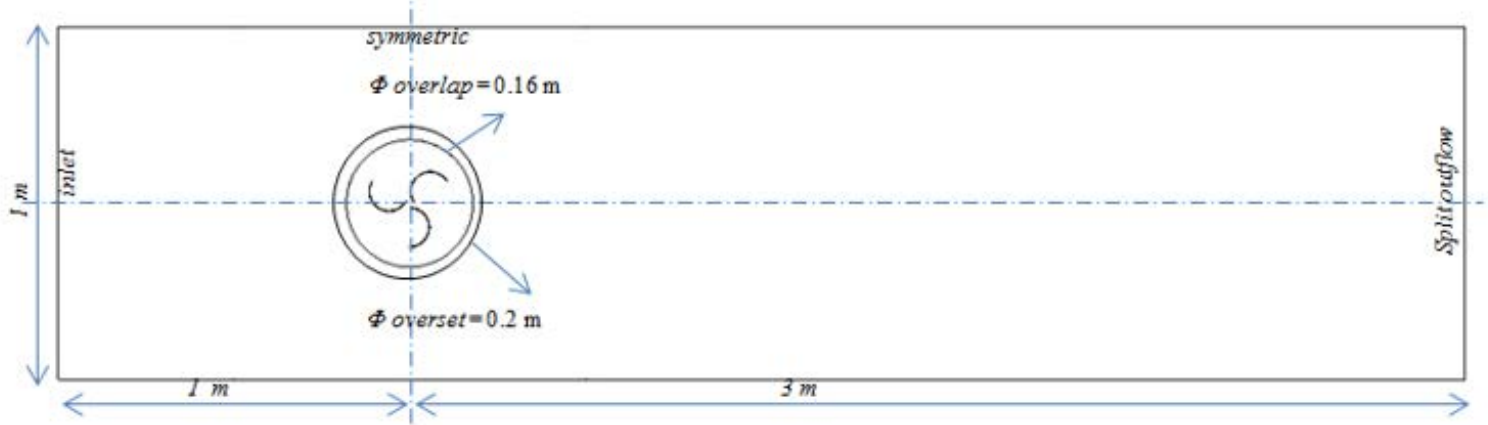

(a)

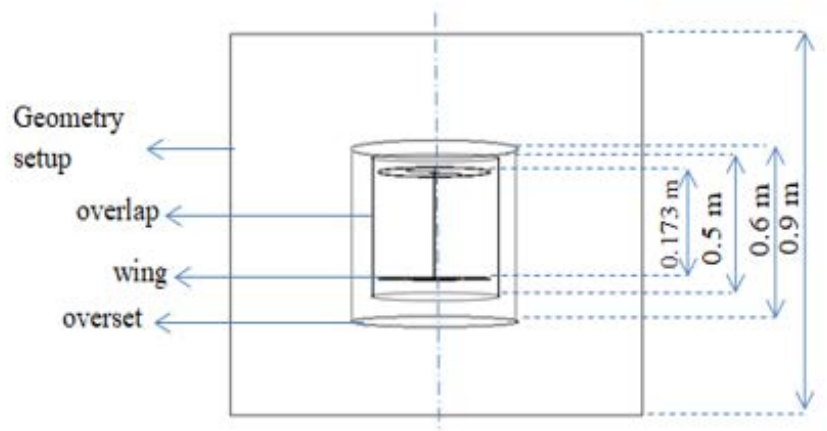

(b)

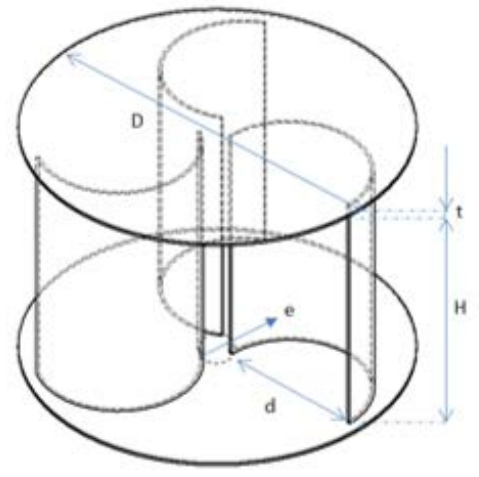

(c)

Figure 1. (a) Boundary condition and size of test section (a) above (b) side (c) Savonius.

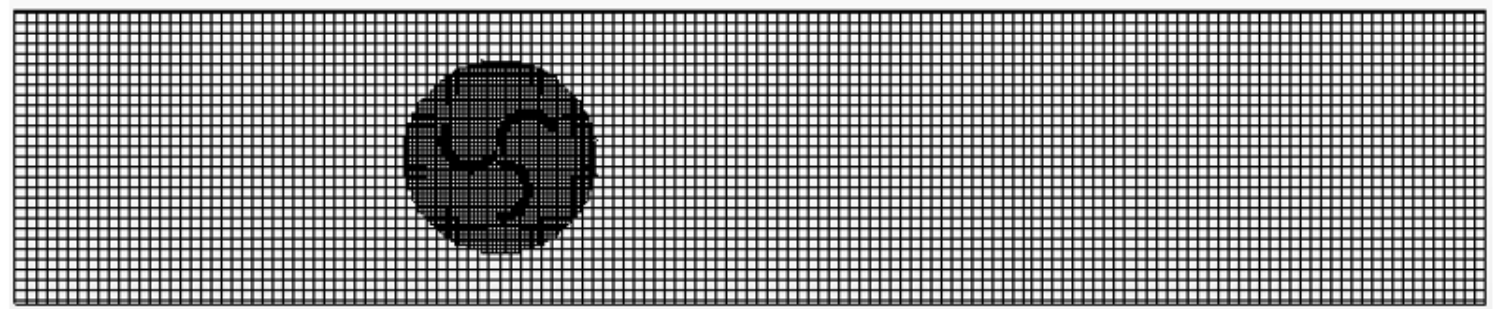

(a)

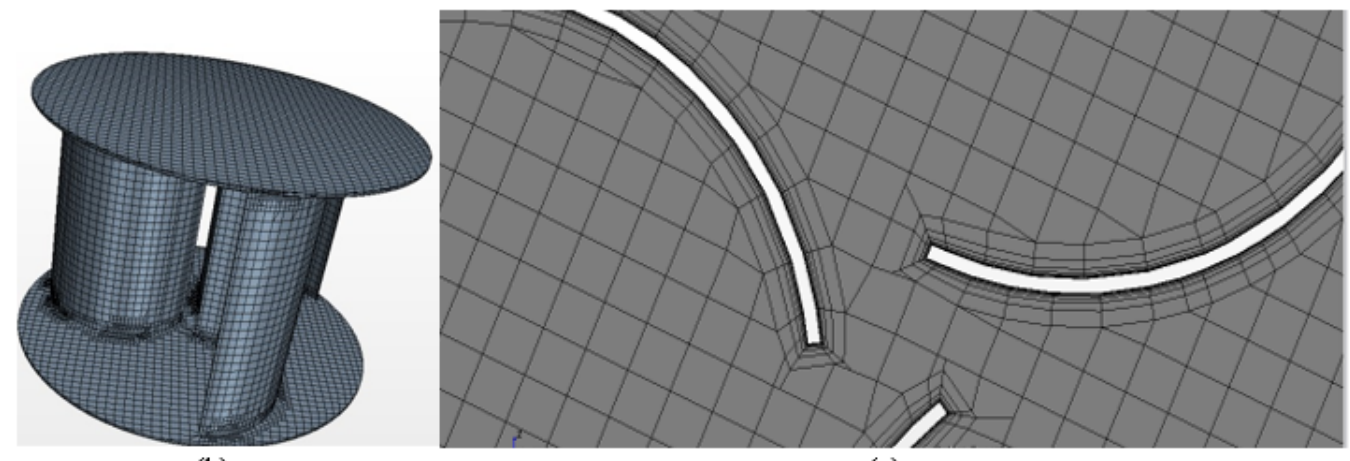

(b)

(c)

Figure 2. (a) Boundary condition and size of test section (a) above (b) side (c) Savonius. 
Angular Velocity 1-DOF simulation

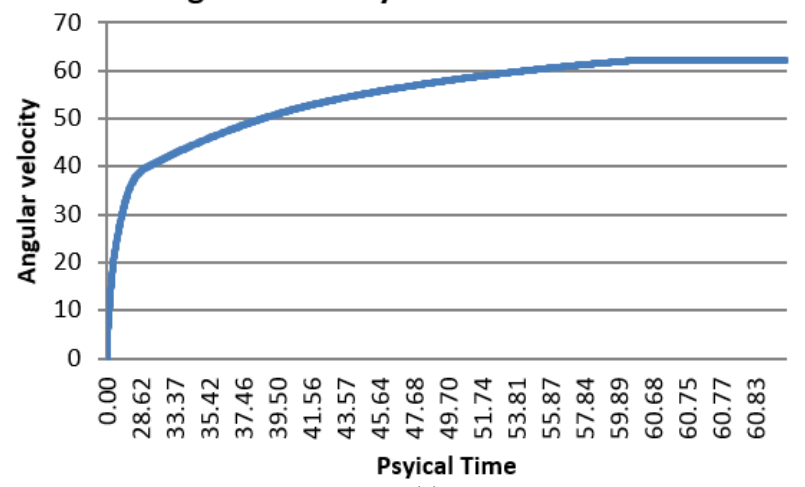

(a)

\section{Moment 1-DOF simulation}

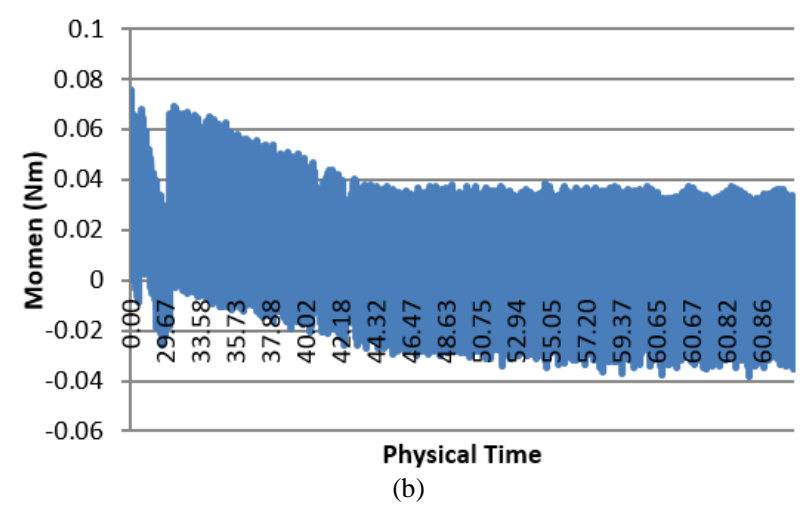

Figure 3. Numerical simulation result 1-DOF simulation in physical function (a) angular velocity (b) phisical time.

\section{$C_{p}$ Savonius Endplate}

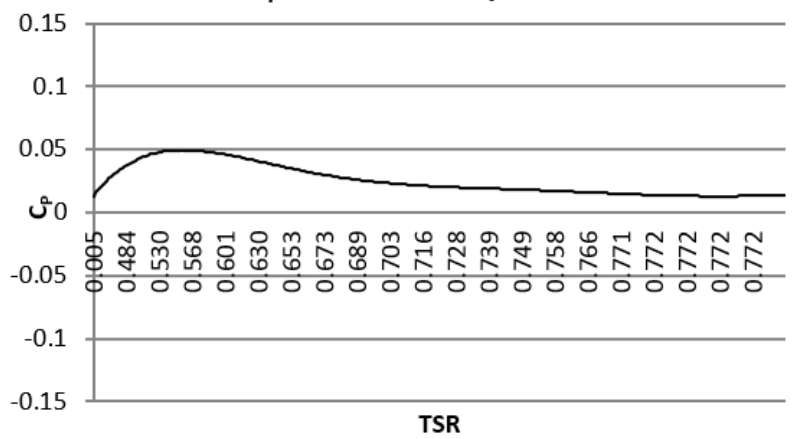

(a)

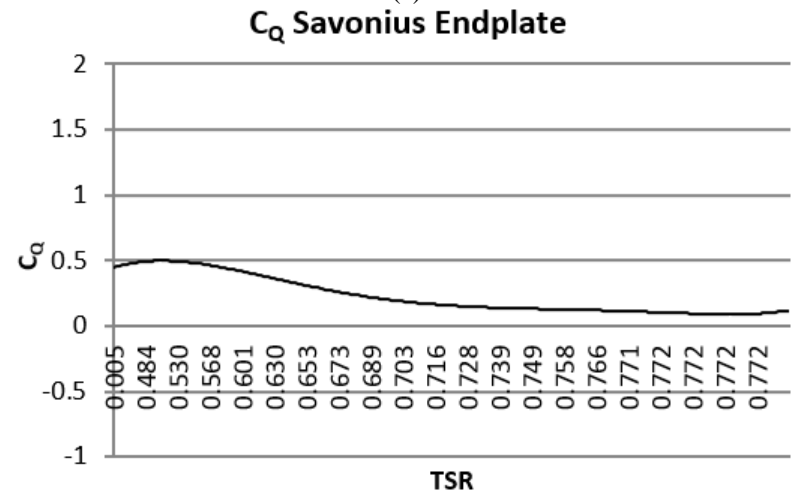

(b)

Figure 4. Dimensionless numerical simulation result 1-DOF simulation in TSR (a) angular velocity (b) phisical time.
TABLE 1.

BOUNDARY CONDITION IN NUMERICAL SIMULATION

\begin{tabular}{|c|c|c|}
\hline Boundary & Input & Value \\
\hline \multirow{2}{*}{ Fluid } & $\rho$ & $1.225 \mathrm{~kg} / \mathrm{m}^{3}$ \\
\hline & $\mu$ & $1.86 \times 10^{-5} \mathrm{~N} . \mathrm{s} / \mathrm{m}^{2}$ \\
\hline \multirow{3}{*}{ Inlet } & Velocity inlet & $6 \mathrm{~m} / \mathrm{s}$ \\
\hline & Turbulence intensity & $4 \%$ \\
\hline & Length scale & $0.01 \mathrm{~m}$ \\
\hline \multirow[t]{3}{*}{ Outlet } & Pressure outlet & $0 \mathrm{~Pa}$ \\
\hline & Rotating & $\mathrm{y}$ axis \\
\hline & Material & Galvanized Iron \\
\hline \multirow[t]{3}{*}{ Wing } & $\rho$ & $7870 \mathrm{~kg} / \mathrm{m}^{3}$ \\
\hline & Massa & $3.1305 \mathrm{~kg}$ \\
\hline & Moment inertia & 0.017175 kg.m $\mathrm{m}^{2}$ \\
\hline \multirow[t]{2}{*}{ Residual } & Minimum & $10^{-4}$ \\
\hline & Implicit second order & \\
\hline \multirow[t]{2}{*}{ Unsteady } & Time step & Base on CFL > 5 \\
\hline & Inner iteration & 100 iteration /time step \\
\hline Model & \multicolumn{2}{|c|}{ RANS Segregated flow $k-\omega S S T$} \\
\hline
\end{tabular}

TABLE 2.

NUMBER OF MESH IN NUMERICAL SIMULATION

\begin{tabular}{cccc}
\hline \hline Jumlah sel & $\mathbf{y}^{+}$ & Momen & Eror \% \\
\hline 631729 & 0.262 & 0.0207 & - \\
735180 & 0.251 & 0.021954 & 5.68 \\
899768 & 0.197 & 0.021621 & 1.54 \\
1116522 & 0.267 & 0.02119 & 2.05 \\
1296710 & 0.220 & 0.020955 & 1.11 \\
\hline \hline
\end{tabular}

TABLE 3.

DIFFERANCE IN STATIC AND FSI 1-DOF C $\mathrm{C}_{\mathrm{Q}}$ VALUE

\begin{tabular}{llc}
\hline \hline Method & CQ & Diffrance \\
\hline Static & 0.4557 & \\
FSI-1 DOF & 0.5035 & 9.4938 \\
\hline \hline
\end{tabular}

\section{REFERENCES}

[1] F. Wenehenubun, A. Saputra, and H. Sutanto, “An experimental study on the performance of Savonius wind turbines related with the number of blades," Energy Procedia, vol. 68, pp. 297-304, Apr. 2015.

[2] K. S. Jeon, J. I. Jeong, J.-K. Pan, and K.-W. Ryu, "Effects of end plates with various shapes and sizes on helical Savonius wind turbines,” Renew. Energy, vol. 79, pp. 167-176, Jul. 2015.

[3] T. Wakui, R. Yokoyama, and H. Arase, "Influence of load level on performance of standalone vertical axis wind turbine system," Wind Eng., vol. 33, no. 3, pp. 213-235, May 2009.

[4] J. V. Akwa, G. Alves da Silva Júnior, and A. P. Petry, "Discussion on the verification of the overlap ratio influence on performance coefficients of a Savonius wind rotor using computational fluid dynamics,” Renew. Energy, vol. 38, no. 1, pp. 141-149, Feb. 2012.

[5] M. Shaheen, M. El-Sayed, and S. Abdallah, "Numerical study of two-bucket Savonius wind turbine cluster," J. Wind Eng. Ind. Aerodyn., vol. 137, pp. 78-89, Feb. 2015.

[6] A. Al-Faruk and A. Sharifian, "Flow field and performance study of vertical axis Savonius type SST wind turbine,” Energy Procedia, 
The $4^{\text {th }}$ International Seminar on Science and Technology August $9^{\text {th }}$ 2018, Postgraduate Program Institut Teknologi Sepuluh Nopember, Surabaya, Indonesia

vol. 110, pp. 235-242, Mar. 2017.

[7] P. Jaohindy, H. Ennamiri, F. Garde, and A. Bastide, "Numerical investigation of airflow through a Savonius rotor," Wind Energy, vol. 17, no. 6, pp. 853-868, Jun. 2014.

[8] M. Tahani, A. Rabbani, A. Kasaeian, M. Mehrpooya, and M. Mirhosseini, "Design and numerical investigation of Savonius wind turbine with discharge flow directing capability," Energy, vol. 130, pp. 327-338, Jul. 2017.
[9] U. K. Saha, S. Thotla, and D. Maity, "Optimum design configuration of Savonius rotor through wind tunnel experiments," J. Wind Eng. Ind. Aerodyn., vol. 96, no. 8-9, pp. 1359-1375, Aug. 2008.

[10] M. Hadi Ali, "Experimental Comparison Study for Savonius Wind Turbine of Two \&amp; Three Blades At Low Wind Speed," Int. J. Mod. Eng. Res., vol. 3, no. 5, pp. 2978-2986, 2013. 